\title{
Digitalisation for smarter cities: moving from a static to a dynamic view
}

\section{Timea Nochta PhD}

Research Associate, Centre for Smart Infrastructure and Construction, Department of Engineering, University of Cambridge, Cambridge, UK (corresponding author: tn328@cam.ac.uk) (Orcid:0000-0003-1804-0601)

\section{Li Wan PhD}

Lecturer, Department of Land Economy, University of Cambridge,

Cambridge, UK

Jennifer Mary Schooling OBE, PhD

Director, Centre for Smart Infrastructure and Construction, Department of Engineering, University of Cambridge, Cambridge, UK
Charlotte Lemanski PhD

Senior Lecturer, Department of Geography, University of Cambridge, Cambridge, UK

Ajith Kumar Parlikad PhD

Senior Lecturer, Institute for Manufacturing, Department of Engineering, University of Cambridge, Cambridge, UK (Orcid:0000-0001-6214-1739)

Ying Jin PhD

Senior Lecturer, The Martin Centre for Architectural and Urban Studies, Department of Architecture, University of Cambridge, Cambridge, UK

This paper presents a critical review of the literature on smart cities informed by a sociotechnical perspective that views 'smart city development' as a dynamic change process that extends to both the technological apparatus of the city and the social environment that produces, maintains and uses it. The conclusions from the review are summarised in six propositions. The propositions contest the mainstream discourse that often culminates in a utopian vision where data collection, processing, analysis and sharing provide solutions to all urban problems and provide direction for the future advancement of smart city research and practice. Using the propositions as guidelines to underpin a multidisciplinary approach, the paper sets out a relational perspective based on notions of boundary spanning, coordination and management that can shed light on previously overlooked aspects of smart city transitions.

\section{Introduction: the process perspective on smart city development}

The smart city notion started appearing from the 1990s, initially as a supply-side-driven practice-orientated agenda, but it soon caught the interest of scholars working in various fields of research, including, but not limited to, engineering, computer science, public policy and administration and human geography. The mainstream smart city narrative has been, and still is, dominated by a distinct focus on technology as the enabler for cities to become more instrumented, interconnected and intelligent through capturing and collecting, sharing and distributing and analysing and implementing data (Harrison et al., 2010). However, links to urban development goals and city challenges remain obscure and indirect.

In response, a critical literature started to develop in the social sciences which condemns the mainstream narrative for its focus on technologies, seeing their implementation as necessary to achieve smarter urban living, while downgrading citizens to subjects and their role in this process to passive users of smartdigital technologies needing to adapt to the emerging digital revolution (see e.g. the publications by Datta (2015), Luque-Ayala and Marvin (2015), Kitchin (2016), Kitchin et al. (2017), Rose (2017) and Martin et al. (2018)).

Nowadays, smart city development is considered the norm, and the necessity of moving towards smarter cities has been accepted as inevitable and indisputable. However, a conceptual understanding of what exactly makes a city smart is still lacking despite the abundance of characterisations, classifications and evaluation frameworks for smart initiatives (Albino et al., 2015; Cavada et al., 2017; Neirotti et al., 2014). The absence of supporting theories and clear value propositions translates into fragmented, piecemeal initiatives, resulting in impact detached from idealised smart city visions.

To remedy this shortcoming, the authors argue for the benefits of considering smart city development as a dynamic change process worthy of investigation in its own right rather than simply as the 'natural' pathway towards the smart city as a static, normative goal. Smart city development is understood here as a continuous process of adoption of innovative technologies to improve the functioning of cities and the quality of urban life. Informed by contemporary discourse, this paper focuses specifically on datadriven digital technologies and techniques.

As through technological and social advancement cities and technologies can always become smarter, static approaches inevitably lead to difficulties with identifying an end point where the city achieves a 'smart' state. The shift in focus towards a process perspective allows for linking the smart city agenda to existing knowledge and literature around concepts of systems thinking, sociotechnical and sustainability transitions, public- and private-sector innovation and organisational and social learning. The aim is to establish an understanding of how better links can be built between the technology-focused, deterministic and generally positive discourse on the one hand and the critical, society-focused and sceptical voices on the other hand in order to advance smart city research and practice - which may promote technology adoption in some cases or contexts but also oppose it in others.

Based on a critical reading of the literature on smart cities informed by a sociotechnical perspective, the paper argues the following. 
- (P1) Cities are complex, sociotechnical systems of systems. Smart city development as a process therefore needs to be understood as a result of various sociotechnical transitions within and between city systems, involving both radical shifts and incremental improvements.

- (P2) Developing a proactive approach to smart city development with the aim of containing (or mitigating) the risks associated with deploying new technologies requires investigation into the underlying contextual (e.g. social, cultural, political, economic and environmental) factors that affect the nature and rate of the diffusion of smart innovation in different cities.

- (P3) Prioritised agendas will need to be developed to support a wide range of smart development trajectories in different cities aspiring to pioneer smart city transitions.

- (P4) In order to facilitate smart city development, the introduction of digital solutions into any urban setting must contribute to adapting governance structures and processes to the requirements and opportunities of the contemporary era.

- (P5) The outcome-oriented reorganisation of public services represents a window of opportunity to exploit the potential of digital technologies and counteract certain negative effects of organisational and institutional fragmentation by way of integration and improvement of interoperability and thereby facilitate smart city development.

- (P6) Decision-making about the smart development of cities needs to involve various forms of trust building between the public and the private sectors and citizens. This will support organisational and institutional changes in local authorities internally, as well as relative to other levels of government, the market sector and citizens in order to deliver aspired citylevel outcomes.

These arguments are used to underpin the necessity of developing a relational approach to the process and impact of digitalisation in the urban context in order to direct digitalisation towards the development of smarter cities.

The paper is structured as follows. Section 2 presents a review of the literature on innovation and transitions with a focus on technology and its impact on the social world. Section 3 repeats this exercise, taking governance (urban and also beyond) as a starting point and discussing its impact on the adoption and implementation of innovative technologies. Section 4 considers the nexus of the two approaches and outlines the benefits of a relational perspective to investigate and facilitate debates about the opportunities, risks and limitations of digital solutions in boundary spanning and boundary management. The authors conclude that smart city development cannot and should not be misinterpreted as a merely technical-managerial issue. Instead, further research, experimentation and debate are necessary to grasp the potential of the newly developing digital dimension of cities to reorganise relationships and interactions among entities and objects in both the social world and the built (and natural) environment. This will contribute to a better understanding of how digitalisation might contribute to the development of smarter cities.

\section{Technology in smart city development}

The smart city agenda has initially been shaped through a mainly technology-focused discourse dominated by the supply side (technology providers) and the market logic. Decades later, the 'smart city' as a normative goal is still often described in terms of a contemporary urban utopia promising to 'fix' the city through the use of data and digital technologies supporting city planning and management and the delivery of services (Anthopoulos, 2017; Goodspeed, 2014; Townsend, 2013).

Academic research interest developed alongside early experimentation and implementation of smart city pilot initiatives seeking to make sense of the emerging phenomena. Several attempts have been made to define, characterise and rank smart cities and smart interventions and to anticipate and evaluate their impact in various urban settings (see e.g. the publications by Nam and Pardo (2011), Lombardi et al. (2012), Cocchia (2014) and Neirotti et al. (2014)).

Although partially overlapping, the different perspectives are distinct in terms of their focus and interpretation of smartness (cf. Cavada et al., 2017). Consequently, establishing an inclusive and comprehensive smart city definition and framework(s) for implementation appears to be difficult, if not impossible. The authors therefore argue that putting more emphasis on smart city development as a dynamic change process offers a productive approach to advance the smart city agenda in both research and practice. This process perspective highlights that cities are in fact continuously becoming smarter through innovation including technological as well as social advancement and that identifying an end point when they can be considered smart (i.e. when the process ends) is inherently problematic. Introducing a sociotechnical systems perspective, the authors propose the following.

(P1) Cities are complex, sociotechnical systems of systems. Smart city development as a process therefore needs to be understood as a result of various sociotechnical transitions within and between city systems, involving both radical shifts and incremental improvements.

Studies into historical sociotechnical transitions focus on the role of technological innovation in bringing about social, institutional and economic change - for example, the shift from sailing ships to steamships (Geels, 2002) or from horse-drawn carriages to automobiles (Geels, 2005). 'Transitions' here refer to systemic change unfolding over a comparatively short period of time between two periods of relative stagnation. They occur when shifts in the different domains strengthen one another, resulting in self-reinforcing loops and ultimately reconfiguring entire sociotechnical systems (Rotmans et al., 2001).

Geels and Schot (2007) provide an overview of the different types of change processes which may be components of systemic 
transitions, signalling that different innovative technologies possess varying potential to alter the direction of societal development. Certain technologies may be unable to break through and as a result are abandoned as failed attempts to innovate (Geels and Kemp, 2007) due to the existence of a social selection environment termed as the 'sociotechnical regime'. Regimes in this literature are understood as sets of rules representing the 'cognitive and normative framework and a set of (functional) relationships between technology components and actors' (Hoogma et al., 2002: p. 19) - for example, these may include formal (e.g. written laws) and informal (e.g. culture and traditions) rules and norms influencing user behaviour and values.

Sociotechnical transitions are likely to involve stepwise processes of reconfiguration rather than abrupt shifts from one regime to another. They, however, lead to substantial changes in the functioning of societies and therefore are possible to recognise from a historical perspective (Geels, 2002; Geels and Schot, 2007). Due to the complexity of interactions between the emerging new technologies and the sociotechnical regimes, real-world transitions emerge from a mix of radical shifts that challenge and reconfigure established ways of doing, as well as incremental improvements making existing practices more competitive (for a more detailed discussion on incremental and radical change, see e.g. the papers by Rotmans et al. (2001), Garcia and Calantone (2002) and Genus and Coles (2008)). The new regime is then assembled from a combination of these radical and incremental changes.

The impact of technology, in particular infrastructures, has also become a central question in contemporary urban studies debates in opposition to the engineering perspective. Scholars have started challenging the dominant conceptualisation of urban infrastructure as being exclusively technical (see e.g. the papers by Star (1999), Amin (2014), Lancione and McFarlane (2016) and Knox (2017)). Instead, they point to the importance of considering the ways in which it is embedded in human actions and relationships and to the necessity of employing a multidisciplinary approach spanning the physical and social sciences when it comes to examining the impact of technologies on society and vice versa.

Based on studies from a variety of contexts from across the Global North (Swyngedouw, 2009; Young and Keil, 2010) and South (Anand, 2017; Monstadt and Schramm, 2017), it has been proposed that considering infrastructure as a sociotechnical construct is crucial to understanding contemporary urban societal life. One notable example is the case of increasing concern over unequal access: the term 'splintering urbanism' (Graham and Marvin, 2001) was introduced to describe the exclusionary and fragmentary effects of privatising infrastructure provision. Driven by market rationalities, urban splintering is both spatial and social, dividing cities into well-connected and underconnected zones, with societal consequences for poverty and inequality.

Thus, while historically infrastructure was viewed as neutral or technocratic, Graham and Marvin's approach reveals how it may become a tool of social power that can extend and perpetuate inequality, connected to broader processes of exclusion and marginalisation and ultimately to citizens' rights. Similar issues have also been identified by Watson (2014) in the case of proposed smart city projects in Africa and by Datta (2015) in India, which prioritise international investment exploiting political ambitions of the local elite, at the expense of marginalised communities.

The lesson to be learnt for smart city research and implementation is that the development of smarter cities is by no means a merely technological question and, by extension, smart technologies do not provide society with a blank page or a clear new start. The prospect of smart city technologies emerging as radical innovation in the context of cities as systems of systems interconnected in complex ways (Rogers, 2018), and eliminating all existing urban problems at once, is rather unlikely. Instead, a continuous process of technological and social innovation appears to be necessary to respond progressively to the challenges and unintended consequences arising along the way. Specifically, in the case of developing smarter cities, this involves a more proactive stance from government and citizens to counterbalance the traditional technology-focused, supply-side-led perspective on smart cities.

The sociotechnical perspective thus points to the need for building a better understanding of whether specific smart city technologies can or should be employed in particular cities. This involves assessing the structure and stability of the locally relevant sociotechnical selection environment (regime) and evaluating its impact on the adoption of the technology in question. Thereafter, the implications of the expected change resulting from the deployment of this technological solution must be considered in light of the views, needs and aspirations of citizens as individuals and as members of communities and urban societies (see also the report by Rogers et al. (2014)). This observation leads to the authors' second proposition.

(P2) Developing a proactive approach to smart city development with the aim of containing (or mitigating) the risks associated with deploying new technologies requires investigation into the underlying contextual (e.g. social, cultural, political, economic and environmental) factors that affect the nature and rate of the diffusion of smart innovation in different cities.

It has been notoriously difficult to estimate the practical impact of deploying smart city solutions in real-world urban settings. As an early critic of the technology-driven smart city agenda, Hollands (2008) argued that the assumption that hardware connectivity made possible by the emerging digital technologies would naturally transform citizens, businesses and governments into a connected whole - and therefore emerge as a radical innovation in the context of urban life - has been mistaken. Furthermore, while most smart city initiatives are explicitly aimed at delivering sustainable urban development, commentators from various countries have questioned their practical contribution to environmental sustainability (Haarstad, 2017; Yigitcanlar and 
Kamruzzaman, 2018). Negative environmental externalities have also been identified in the case of smart cities built from scratch, such as Songdo in South Korea (Shwayri, 2013).

With regard to impact on citizens and urban societies, the more critical view originating from the social sciences is becoming increasingly acknowledged by a wider set of actors in smart city research and practice. This asserts that purely technology-focused solutions are, in most instances, incapable of solving deep-rooted structural problems in cities as they do not address the root causes which produce and re-produce them (Hollands, 2015; Kitchin, 2014; Martin et al., 2018). As an alternative to the technology-led smart city visions, many scholars identified the potential to empower people (citizens) to make informed decisions in both private and public domains as the core value of smart city development (Capdevila and Zarlenga, 2015; Hemment and Townsend, 2013; Monfaredzadeh and Krueger, 2015). The smartness of people started to replace smart technology as the key enabler of smarter cities even in the mainstream discourse (Arup and FCC, 2017) - at least in terms of rhetoric.

However, the impact of this conceptual shift is still unclear, as revealed in the recent global review of smart city demonstrators conducted by the UK Future Cities Catapult (FCC, 2018). Investigating over 150 large-scale smart city interventions, the findings indicate that 'despite the continuous rhetoric around the smart city agenda seeking to solve city challenges, many demonstrators have ended up as technology demonstrations. A need has been identified for societal challenge-based demonstrators that place city issues front and centre' (FCC, 2018: p. 7). Although the studied smart city demonstrators cover a wide range of policy domains, very few present technology as part of a comprehensive solution package that would explicitly aim to address a specific urban challenge - for example, those aimed at improving existing services to end users (e.g. city services, smart healthcare and last-mile supply chain) tend to include a stronger linkage between the technology and the manifested practical outcomes. In contrast, those named after technologies (e.g. connected and autonomous vehicles and 5G) focus primarily on demonstrating technical functionality.

The review highlights another aspect of the challenge related to considering societal impact when designing and implementing smart city interventions: the gap between technology deployment and considering demand - that is, the specific urban challenge(s) to which the innovation responds. Conceptualising demand and developing a problem framing of the challenge(s) to be addressed where technological solutions may be applicable is, however, an extremely problematic undertaking. Smart city initiatives often promote a simplistic view of participatory decision-making without a sufficient consideration for the impact of politics, power relationships and struggles and conflicts of interest in contemporary societies. In contrast, several studies have demonstrated that participatory processes are inherently prone to elite capture, often reproducing the very issue that they aim to solve (Ghertner, 2011; Lemanski, 2017).
Therefore, there appears to be a gap in knowledge around the nature, form and extent of mediation processes between the interests and demands of different groups, entities and individuals which is necessary to ensure that smart city interventions deliver on the aspired city-level outcomes. Recent and currently ongoing research and consultation activities (see e.g. the publications by Rogers et al. (2014), Leach et al. (2018), Robinson (2018) and The Ove Arup Foundation (Toaf, 2019)) have recognised this gap and have been generating valuable guidelines and insights. However, there is still much to learn about how local contextual conditions related to culture, politics, economics and the environment influence - or should influence - the nature and rate of diffusion of different specific digital solutions and the make-up of smart city transitions in terms of radical shifts and incremental improvements. A mediation process between various interests and society as a whole provides a useful framing for a more proactive approach from city authorities and citizens. Including diverse perspectives in the discussion can contribute to anticipating the implications and containing the risks of deploying new technologies, particularly when such deployment is regarded as radical or disruptive in the context of existing urban challenges. Identifying strategic overlaps between supply and demand this way can potentially uncover specific windows of opportunities where impact can be delivered to build trust in, and competence for, the use of data and digital technologies for city planning and management not only for, but also together with, citizens. This is particularly important in the current political discourse dominated by austerity which tends to favour investment and interventions where evaluation can be completed and clear benefits can be shown within rapid timescales. Thus, asking the right question(s) where both impact (i.e. addressing a pressing city challenge) and benefits (i.e. addressing this challenge appropriately) can clearly be demonstrated is vital to advancing the development of smarter cities.

Furthermore, the variance in terms of challenges to be solved in different cities signals the importance of recognising the following.

(P3) Prioritised agendas will need to be developed to support a wide range of smart development trajectories in different cities aspiring to pioneer smart city transitions.

Some form of a prioritisation scheme appears as an appropriate choice to make the best of limited political and financial resources to tackle major urban challenges while also enabling agenda refinement along the implementation in a learning-by-doing manner. As all cities differ in their history and economic and political make-up, these prioritisation schemes cannot be developed out of context. Inquiry into the options for prioritisation could help to develop road maps for smart city transitions, provide opportunities to redefine the smart city narrative locally by including the voice of citizens and potentially strike a balance between short- and long-term investments. The authors argue that the approaches based on forecasting (Leach et al., 2018) and developing pathways towards systemic changes 
by way of backcasting (Bibri, 2018; Phdungsilp, 2011) could be supported and strengthened by a more process-oriented perspective on smart city development which generates insights on how prioritisation may be affected by the local urban context.

Given the multiplicity of city functions, it is reasonable to expect that digitalisation is unlikely to take place simultaneously across the entire spectrum, as not all urban problems lend themselves automatically to data-driven solutions (Hollands, 2015; Rabari and Storper, 2015). Smart city development may have a more direct and immediate impact on some policy domains, whereas for others such impact may be indirect, take a long time to materialise or may even be marginal (Berkhout and Hertin, 2001; Tarute and Gatautis, 2014).

It may be tempting to prioritise smart city initiatives on a sectoral basis. Neirotti et al. (2014) reviewed the thematic focus of more than 70 existing smart city initiatives from across the world. Initiatives have been categorised into five thematic groups: natural resources and energy, transport and mobility, buildings, living, government, and economy and people. The fact that the majority of these categories correspond to sectoral silos indicates that most smart city initiatives are not cross-cutting. This, from the sociotechnical perspective, provides at least partial explanation for the issue often referred to as 'pilot sickness', describing the difficulties involved in upscaling pilots to citywide systemic change (Arup and FCC, 2017). In established sectoral silos, smart city interventions may be subject to stronger processes of selection or adoption from the sectoral sociotechnical regimes. Consequently, their potential to challenge the existing system and to maximise benefits - may remain limited.

Recent publications from the BSI on smart cities attempted to address the issue of silo-isation. PAS 181:2014, 'smart city framework' (BSI, 2014), published by the BSI provides guidance on developing strategies for smart city and community development. It calls for a new operating model for cities through innovative use of technology and data - coupled with organisational changes. The framework recognises that, because the traditional ways of city operations feature scarcely connected vertical silos, individual citizens and businesses have had to engage separately with each silo as data have typically been locked within these - including energy, waste, water, telecommunications, policing and emergency response, education and training, transport, health, social services, housing, environmental services and finance and economy. In order to transcend such vertical silos, data and technology must be reoriented to address user needs, and data must be managed as an asset in its own right to foster both public- and private-led innovations. While PAS 181:2014 sets out the task of integration and improvement of interoperability across infrastructures (e.g. energy, transport or water), services (e.g. healthcare, social care and education) and city functions (e.g. employment, culture and leisure), practical guidelines for implementation to support the shift from the conventional to a smarter model are lacking.
Exposing cross-silo dependencies and interdependencies through infrastructure and urban systems mapping may provide a starting point to address this issue (Leach et al., 2018; Rogers, 2018), but further work is necessary to explore how silo-isation might be addressed in the context of digitalisation for smarter cities.

Misalignment between demand in different urban contexts and uniformised technology offerings is another potential obstacle to upscaling pilot initiatives. As Batty (2017) also points out, the areas of existing smart city initiatives tend to be based on where sensors, networks and computers can be deployed and sold, rather than being based on any distinct theory of how smart cities, enhanced by data and digital technologies, could and should function in different places around the world. Although more and more are engaging with the smart agenda, often no local strategy is in place to coordinate initiatives of varying spatial-temporal scale and manage the associated multisectoral and multidisciplinary collaborations and joint ventures. Even in cities at the forefront of smart development, organisational structures and processes - which could ensure that a wide range of opinions, interests and needs are considered - tend to lag behind.

London is a good example to illustrate the impact of organisational structures and processes on the smart agenda. Back in 2013, the first version of the Smart London Plan stressed the market opportunities offered by the digital revolution, stating that any delay in getting 'on board' would result in negative consequences: 'Rapid growth of mobile internet applications, the internet-ofthings, cloud computing and insights from big data, offer new business opportunities and can enhance quality of life... Missing these opportunities could leave us in second place for years to come' (GLA, 2013: p. 3). Driven by change on the political level, putting some initial organisational structures and processes in place in the subsequent years (and opening up the debate to a wider range of stakeholders and citizens) has contributed to a shift in emphasis. The new road map published in 2018 aims to 'put people first' and highlights the need for respecting diversity with regard to technology adoption - and for giving more voice to citizens through establishing citywide collaborations and networks around specific smart city goals (GLA, 2018).

The currently dominant overemphasis on technology leads to limited impact and 'pilot-itis' in the context of smart city development. In practice, the mainstream adoption of digital technologies to ease city life, and the upscaling of pilots, involves a multiplicity of local decisions subject to various political, social, economic and technical constraints, in contrast to the dominant universal and deterministic narrative around smart cities often promoted by multinational corporations for profit-making purposes. Solving urban challenges is a messy, non-linear and political process with winners and losers. As such, it arguably needs to involve a citywide discourse around the social, economic and environmental benefits and costs of various solution packages with diverse technological elements, used at different temporal-spatial scales, instead of relying on the game-changing 
potential of technology alone. Interdependence between the physical-material and social systems, digital solutions and the local potential for change (not only through the adoption of innovative technologies, but also the possibilities to change social rules - legislation or policies - norms and practices) must also be investigated and articulated.

\section{Governance in smart city development}

In the previous section, the authors investigated smart city transitions from a sociotechnical perspective, departing from technology adoption as a starting point. This takes on board the frequent criticism of the sociotechnical perspective that it features an inherent bias towards the technology component of change processes while potentially downplaying the complexity of interactions between societal change and technology advancement. Societal change, as well as technological advancement, may emerge both in its own right and a result of influence and interactions between the two. To remedy this shortcoming, in the following section, the authors start the discussion from a societal perspective and use the concept of 'governance' (Meuleman, 2008; Rhodes, 1996; Torfing and Sørensen, 2014) to analyse society's role in influencing technology innovation and adoption for smart city development. Governance allows for a broad understanding of social coordination processes, encompassing all decisions made by all affected and/or interested actors - in this case city planning, management, operation and use. It also stresses that real-world outcomes result from the sum of diverse coordination structures and mechanisms which include local and higher-level authorities, service providers and the interactions between them, as well as users and their everyday choices - conditioned by both formal rules and informal norms.

The authors argue that there is a benefit to considering smart city transitions within a broader context of urban governance and its trajectory over time. After all, smart city development does not take place in a vacuum. Instead, the digital revolution offers a collection of new tools and processes which carry the potential to improve the functioning and governance of cities to deliver outcomes that meet citizens' needs in the contemporary era (cf. Rogers, 2018). It follows

(P4) In order to facilitate smart city development, the introduction of digital solutions into any urban setting must contribute to adapting governance structures and processes to the requirements and opportunities of the contemporary era.

The development of smarter cities entails the development of smarter urban governance, potentially requiring both organisational and institutional changes. Although it may be tempting to consider this as a unique issue and without precedent, the public sector has continuously been introducing reforms aimed at making governance more efficient and effective and responding to challenges more adequately. These reforms have often started from classical Western democracies but later on spread to a wide variety of countries.
Meijer and Bolívar (2016: p. 392) see smart transitions in governance as 'crafting new forms of human collaboration through the use of information and communication technologies'. The emphasis on collaboration is in line with contemporary public administration debates around the emergence of a new type of social coordination termed 'network governance' based on collaboration, participation and interaction and negotiations among interested and/or affected societal actors within and beyond the public sector (see e.g. the papers by Torfing (2005), Torfing and Sørensen (2014) and Klijn and Koppenjan (2015)). The attention to various networked arrangements is often attributed to two major problems in contemporary governance: organisational and institutional fragmentation and the blurring of boundaries between the public and private sectors. These result in shifting power relationships and the dispersion of power among various entities across the governance landscape and make traditional hierarchical (command-and-control) and market-style coordination (free competition) mechanisms ineffective and impractical in certain policy domains. Governance based on networks in contrast is praised for its perceived superiority in responding to wicked problems through knowledge and resource pooling to deal with complexity, non-linearity and multiple causes and solution options (Klijn and Koppenjan, 2015; Rittel and Webber, 1973).

'Smartening' governance aims explicitly at exploiting the potential of digital technologies and their ability to restructure relationships between different (city) system components, including both social (entities, organisations or individuals) and technological (infrastructures and built environment) (Bolívar and Meijer, 2016). The digital dimension of a city, emerging from data-driven solutions such as infrastructural information, locational and sensing, ubiquitous computing and augmented reality and convergence technologies (Yigitcanlar, 2016), is seen as an opportunity to forge new links and connections for interaction among social and technological system components and thereby contribute to formulating better solutions to pressing contemporary urban challenges. However, it remains unclear how to deal with potential unintended consequences arising from the reorganisation processes. Furthermore, it is questionable whether urban governance problems can be reduced to silo-edness and the lack of connections across the currently fragmented organisational and institutional landscape.

A historical overview highlights that wicked problems are not new phenomena (Rittel and Webber, 1973). For example, in the wake of economic crises in the 1970s, a dominant discourse appeared which encouraged a move away from the welfare state towards a neoliberal 'minimal state' (Rhodes, 1996). The welfare state has become seen as overloaded, unaffordable and, consequently, ineffective in solving pressing societal problems of the era. In response, the public sector was to be made more effective, efficient and responsive to citizens' needs through the introduction of market-style mechanisms and techniques (Pollitt and Bouckaert, 2004, 2011; Skelcher, 2000). The reforms were 
characterised by disaggregation (e.g. the internal restructuration of organisations into compact, specialised units and agencification), competition (e.g. contracting out public services to private companies and internal quasi-markets within government) and incentivisation (e.g. performance-oriented evaluation through output measurement and key performance indicators and performance-related salaries for public officers) (Pollitt and Bouckaert, 2004, 2011).

With regard to infrastructures and services that underpin the functioning of cities (and are subject to digitalisation in smart city development), the recent neoliberal reorganisation of the public sector to focus on core functions involved market liberalisation in previously state-operated sectors, such as energy or public transport, and the privatisation of various state-owned assets - for example, power plants or highways (Graham and Marvin, 2001).

These reforms were seen, at the time, in a similarly positive light in terms of delivering better societal outcomes compared to the existing systems and processes as the development of smarter cities and smarter urban governance is today. However, the impact of market-style reforms in terms of producing other wicked problems is nowadays becoming increasingly acknowledged (Osborne, 2010; Pollitt and Bouckaert, 2011). These predominantly relate to a relatively high degree of organisational and institutional fragmentation within and beyond the public sector, as well as the blurring of boundaries between the public and private sectors. Specific problems arise with regard to decreased potential for coordination, allocating accountability as well as regarding the legitimacy and democratic quality of decisions and decisionmaking (Bekkers and Edwards, 2007; Skelcher, 2000; van Kersbergen and van Waarden, 2009).

The paradigm informed by ideals of participation, networks, partnerships, transparency and trust (Pollitt and Bouckaert, 2011: p. 11) inspired a new wave of reforms starting from the 1990s. These reforms aim to deal with the inherent complexity of decision-making processes in an era when 'no one is in charge' (i.e. no one societal actor possesses the powers and resources to achieve their goals or deliver their tasks without needing to interact with others (Bogason and Musso, 2006)). Alongside the dominant trends of globalisation and urbanisation, the introduction of digital technologies to facilitate smart city development needs to be understood in the context of the emergence of the 'network society' (Castells, 2010).

In governance, this is connected to ideas around networks, collaboration, participation and interaction and negotiations among interested and/or affected societal actors, within and beyond the public sector. Enquiry into future smarter urban governance structures and processes must therefore extend to the opportunities offered by digital technologies to ease organisational and institutional change where this is deemed important and beneficial - for example, to counteract the negative effects of fragmentation. Focusing solely on the necessary social-organisational changes to make use of available or emerging technologies is rather unlikely to bring about the development of smarter cities. This observation puts the authors' fifth proposition into perspective.

(P5) The outcome-oriented reorganisation of public services represents a window of opportunity to exploit the potential of digital technologies and counteract certain negative effects of organisational and institutional fragmentation by way of integration and improving interoperability and thereby facilitate smart city development.

The focus here is on public services as the outputs of urban governance. Three tasks have been set out to be addressed by way of smart transitions in urban governance: first, to identify and mitigate the negative consequences of previous market-style reforms (in countries where these have been implemented); second, to address locally relevant challenges arising from dominant trends of globalisation, urbanisation and the network society; and, third, to find new coordination processes which fit the changing societal perceptions about the role of public and private actors and citizens in public policymaking, implementation and service delivery (Klijn and Koppenjan, 2012; Paskaleva et al., 2017). It has been argued that rendering policy issues governable (i.e. possible to govern) in this context requires a shift towards more reflexive forms of governance where decision-making is facilitated by interactions and negotiations among relevant actors. This entails the reorientation of the role of state (public-sector bodies) towards steering and managing decision-making processes emerging from networks of collaboration. The usefulness of digital technologies therefore may be evaluated according to their potential to aid this change by complementing (or replacing) parallel organisational change processes aimed at reducing fragmentation by way of integration and improving interoperability in public service delivery (Dunleavy et al., 2006; Margetts and Dunleavy, 2013). While the preceding discussion presents the argument mainly from the Western perspective, the issue of fragmentation should not be considered as specific to cities of the Global North. Possibilities for improving service provision through integration and interoperability may also be relevant to the Global South, specifically in relation to the developing hybrid or heterogenous infrastructure configurations and paradigms (see e.g. the publications Anand, 2017; Jaglin, 2015; Monstadt and Schramm, 2017).

The authors refer to 'integration' as an organisational restructuration. Interoperability is understood as the ability of organisations, units or individuals to work together and signifies a processual (institutional) change of developing roles, rules and practices which act as guidelines for collaborative working (Maheshwari and Janssen, 2014). Integration is not always desirable or possible in practice and may ultimately lead to monopoly situations. Counteracting silo-edness by improving interoperability represents another option to improve coordination by making (organisational or institutional) boundaries sufficiently permeable. An example of this is the joining up of various processes of service delivery locked into sectoral silos with a focus 
on outcomes. Improving interoperability requires some form of 'boundary management' (Carlile, 2002, 2004; Kimble et al., 2010).

There are various strands of existing literature concerned with different options for performing boundary spanning and management - for example, collaborative or networked governance, data sharing or intermediaries. Intermediaries may be specific organisations tasked with boundary management (Barrie et al., 2017; Kivimaa et al., 2019), as well as 'objects' (Star, 2010; Williamson, 2015). It is at this point where the potential offered by digital technologies becomes clear: various digital solutions combining digital data collection, management, analysis and automated decisionmaking started to appear as intermediaries in interaction processes among social and technological system elements in various contexts. Objects that perform intermediary functions appear in existing literature as 'boundary objects' (Fong et al., 2007; Star, 2010; Star and Griesemer, 1989; Taylor et al., 2014).

The knowledge base on how boundary spanning and management performed by digital technologies can support the delivery of citylevel outcomes is still underdeveloped, and coordination is lacking. The deployment of digital solutions follows a mostly emergent pattern. New interfaces between previously separate structures or processes emerge organically in the nearly complete absence of any form of coordination or oversight. Consequently, no one can be made responsible and accountable for the outcomes that they produce. Innovation arising in an undirected way through boundary spanning may contribute to the appearance and quick spread of controversial developments, as is well illustrated in cases such as Uber and Airbnb where legislation and regulation have been playing catchup with real-world progress with considerable delay (Edelman and Geradin, 2015; Stone, 2017). Thus, innovation on the fringes, enabled by boundary spanning, represents both an opportunity in terms of its potential 'radicalness' and a risk - for example, in relation to contributing to widening inequality in cities. This point leads back to the responsibility of (local, but also regional and national) governments and the need for developing structures and processes which can better deal with cross-cutting problems, in order to facilitate cross-cutting innovation which serves the city and its citizens.

Viitanen and Kingston (2014: p. 804) argue that '[ $t$ ]echnology can be a powerful tool for analyzing risks or engaging the public in debates ..., but ... "smart" technologies offer no guarantee about the quality of decisions made in cities'. Thus, the 'input' of urban governance - that is, the ways in which decisions affecting citizens are made - must also become integral part of any investigation seeking to understand the impact of digital technologies in cities.

(P6) Decision-making about the smart development of cities needs to involve various forms of trust building between the public and the private sectors and citizens. This will support organisational and institutional changes in local authorities internally, as well as relative to other levels of government, the market sector and citizens in order to deliver aspired city-level outcomes.
Despite the waves of reforms and the introduction of market-style mechanisms and techniques, the ways in which innovative ideas and solutions develop and are implemented in the public sector (including ones concerning its relationship to citizens) are rather different from private-sector innovation taking place in the context of the competitive market economy. Organisational innovation was defined by Choi and Chandler (2015: p. 139) as 'a process through which organizations identify new opportunities to improve their performance by utilizing existing knowledge, seek new knowledge, make revisions, and implement necessary changes'. Thus, organisational innovation involves processes of organisational learning (Dodgson, 1993; Lam, 2000). Potts (2009) investigates how such processes of organisational learning appear in the public sector - and differ compared to the private sector. He argues for the centrality of the concept of efficiency defined in a narrow sense in government by pointing out that 'although considerations of economic efficiency do not ... entirely determine the nature and shape of all public policy and government actions', principles of good governance and effective policy condemn practices that 'go strongly against considerations of economic efficiency’ (Potts, 2009: p. 35).

The quest for more efficiency in public services and decisionmaking - characteristic of the market-style reforms introduced in the second half of the twentieth century - resulted in a tendency to aim at eliminating 'waste' of all kinds from the operation of the public sector - Potts (2009) argues. This, on one hand, is a positive development as it reduces the risk of corruption, exploitation of power and the duplication of efforts ('bad waste'). However, it also reduces the potential for innovation by treating 'good waste' - that is, the cost of innovation - the same way as bad waste. This is problematic as not only are processes of experimentation inherent to innovation, but they also produce substantial waste in the form of failed attempts (Ormerod, 2005; Potts, 2009). In the case of public resources, this is particularly difficult to justify, leading to risk aversion because 'efficiency is an easy political sell' (Potts, 2009: p. 40), while innovation, due to its nature, is hard. What follows from this is the importance of (social and political) trust between the government and the governed when it comes to building an acceptance for good waste as the cost of innovation (Newton et al., 1999; Tolbert and Mossberger, 2006). Trust between the 'governing' and the 'governed' has been defined as the result of the evaluation of whether the normative expectations of the governed (citizens) are perceived as met by the governing (authorities and institutions (Tolbert and Mossberger, 2006)).

Trust-building mechanisms may also contribute to enhancing accountability, legitimacy and democratic quality in public policymaking, implementation and service delivery. For example, specific options available to build trust may involve the (at least partial) transfer of costs, responsibilities and accountability to others (experts, professionals or the citizens themselves) through engagement in joint ventures, partnerships and participative decisionmaking. The conclusions of the report by FCC (2018) discussed 
earlier underpin this argument. It highlights learning areas where city authorities must target better performance, including engagement and access, finance and governance, delivery capabilities and skills, success measurement and scaling (FCC, 2018: p. 11) Recommendations for achieving these include user engagement, stakeholder involvement (sharing responsibilities and accountability) and identifying and ensuring additional and future funding (partial transfer of costs), alongside efficiency and transparency considerations. Therefore, trust-building mechanisms also seek to reduce fragmentation (and promote resource pooling) among the public and the private spheres as well as the civil society. In other words, the options to increase trust between the societal actors with stake or interest in the issues being decided about involve the creation of appropriate flows of information (and influence) across the governance landscape to support smart city development.

In summary, the development of smarter cities - which in its current stage is likely to involve some form of digitalisation to support the planning, management, and operation of cities and urban life - requires and facilitates organisational and institutional changes within the local authority, as well as its relationship to other levels of government, the market sector and civil society. The authors emphasise the central role of local authorities in coordinating and overseeing smart city transitions as they are the main societal actors in the urban context with a unique mandate to safeguard the common good. This includes ensuring that the development trajectory of the city improves, creates and maintains opportunities for all citizens in terms of city-level outcomes. However, the influence and links between city-level (third-order), public-private (second-order) and within-local-authority (first order) changes have so far seldom been considered in the smart city literature and agenda (Kuipers et al., 2014) (for an exception, see the paper by Meijer et al. (2016)). There is a need therefore to understand better how changes within and between these spaces of interaction unfold, are impacted by and impact on the adoption and exploitation of initiatives aimed at smart development.

\section{Bringing together technology and governance}

In the previous sections, the authors provided an extended discussion on smart city development from a sociotechnical perspective, highlighting the benefits of considering it as a dynamic change process instead of a static normative goal or end state. The review maintained a dual focus considering both technological and societal changes as starting points for analysis. The authors contend that technological advancement offers various opportunities to innovate in the context of city planning, management, operation and use. However, the adoption and exploitation of technological solutions must be directed towards improving on the current functioning of city systems (inducing not only their physical-material aspects, but also their governance) and combating contemporary urban challenges faced by many cities around the world. These include - but are not limited to - climate change mitigation and adaptation, urban sprawl, spatial inequality, changing demographics, poor air quality and congestion. Based on the review of the existing literature, six propositions were developed with the intention of framing future research agendas.

- (P1) Cities are complex, sociotechnical systems of systems. Smart city development as a process therefore needs to be understood as a result of various sociotechnical transitions within and between city systems, involving both radical shifts and incremental improvements.

- (P2) Developing a proactive approach to smart city development with the aim of containing (or mitigating) the risks associated with deploying new technologies requires investigation into the underlying contextual (e.g. social, cultural, political, economic and environmental) factors that affect the nature and rate of the diffusion of smart innovation in different cities.

- (P3) Prioritised agendas will need to be developed to support a wide range of smart development trajectories in different cities aspiring to pioneer smart city transitions.

- (P4) In order to facilitate smart city development, the introduction of digital solutions into any urban setting must contribute to adapting governance structures and processes to the requirements and opportunities of the contemporary era.

- (P5) The outcome-oriented reorganisation of public services represents a window of opportunity to exploit the potential of digital technologies and counteract certain negative effects of organisational and institutional fragmentation by way of integration and improvement of interoperability and thereby facilitate smart city development.

- (P6) Decision-making about the smart development of cities needs to involve various forms of trust building between the public and the private sector and citizens. This will support organisational and institutional changes in local authorities internally, as well as relative to other levels of government, the market sector and citizens in order to deliver aspired citylevel outcomes.

In summary, the review pointed out that - in contrast to the largely deterministic and positive narrative that currently dominates the discourse - the development of smarter cities and the technological and social changes that this process implies are neither necessarily straightforward, nor positive, nor, in fact, desirable (see P1 and P2). Nevertheless, the emerging digital dimension of the city, developing gradually from collecting, processing, analysing and making data available from various sources, carries the potential to forge links or improve existing ones within and between currently siloed city functions, among their technological-physical and social-governance components (see P3). The main contribution of this paper argues for the potential benefits of analysing smart city development from a relational perspective, highlighting the importance of considering the city as a sociotechnical system made up of various subsystems and the complex interactions taking place within and between these.

Investigating the opportunities that digital solutions offer for boundary spanning, and the ways in which the process can be 
overseen and scrutinised by individuals as citizens and the urban society as a whole (local authorities and other stakeholders included), provides a potentially fertile field for further research. Ideas around boundary management and boundary objects (Star, 2010; Star and Griesemer, 1989) represent a useful conceptual framing to understand the role of digital solutions in boundary spanning and innovation on the fringes of established city systems. They may also provide society with valuable insights on how to exploit successfully the opportunities that lie in increasing integration, improving interoperability and establishing more appropriate and efficient information and influence flows across the technological and social components that make up the city.

Boundary objects represent non-social-organisational intermediaries which support integration and interoperability by connecting separate systems or entities which have 'different institutional and professional logics or rationales' (Taylor et al., 2014: p. 34). They may take various forms, including, but not limited to, directories (repositories and databases), materialised representations of systems (e.g. physical or digital models), representations of boundaries (e.g. maps and designs) and standardised methods (e.g. standards for data collection or sharing; see also the paper by Trompette and Vinck (2009))

Computerised system models have been analysed as boundary objects performing boundary management between communities of research and practice - for example, in the domain of energy: using the boundary object concept, Taylor et al. (2014) demonstrate that the success and longevity of the Markal model in energy systems modelling supporting energy policy and interventions in the UK lies in its capability to span successfully the boundary and managing interactions between communities of research and practice. Another field relevant to infrastructure planning and management where digital solutions are emerging as boundary objects to support cross-boundary interaction is engineering and design. Here a variety of tools are being deployed to negotiate both the product (e.g. building information modelling, three-dimensional models and computer-aided design drawings (Neff et al., 2010)) as well as associated design and construction processes (e.g. project charts and project management tools (Whyte and Lobo, 2010)).

Further examples that have demonstrated the viability of applying the concept to data-driven digital solutions in relation to various challenges include information technology systems in managing transport in Sweden (Lindgren et al., 2008); a public health system for pinpointing geographic clusters of dangerous/acute disease outbreaks in the USA (Fedorowicz and Gogan, 2010); an Internet portal of services and resources for teachers, students and parents of students in France (Hussenot and Missonier, 2010); and digital geospatial data sharing in the disaster response and recovery process in the USA (Cumbie and Sankar, 2012).

However, the role and impacts of digital technologies interpreted as boundary objects have not been studied so far in the context of smart city development. It is also important to consider that not all solutions originally designed to become boundary objects are successful in making links between separate spheres in practice (Star, 2010). The success of boundary objects has been linked to providing information which is deemed useful as well as usable across relevant groups and individual stakeholders, sectors, scales and disciplines (Dilling and Lemos, 2011) in order to support the transfer, translation and transformation of knowledge across different systems (Carlile, 2004). The usefulness and usability of information have also been framed in terms of salience, credibility and legitimacy (Cash et al., 2003). 'Salience' is interpreted as timeliness and response to demand from intended users which influence the perceived relevance of the information; 'credibility' concerns scientific quality and technical appropriateness; and 'legitimacy' refers to the quality of the process of knowledge production and involves perceptions of fairness, transparency and dealing sufficiently with biases (Cash et al., 2003).

Through the discussions presented in this paper, the authors identified further requirements for digital boundary objects in smart city development. Their potential to reorganise (political as well as economic) power distribution among societal actors from all sectors of societies cannot and should not be ignored or neglected. The ways in which inputs and outputs are generated through governance processes that involve digital solutions must be subject to investigation, debate and scrutiny. Concepts related to collaboration, participation and transparency (input; see P6) and putting citizens' needs first (both as individuals and as a society) when determining city-level outcomes (output; see P5) must become part of the discourse around the introduction of digital solutions to city planning, management, operation and use in future smarter cities.

The development of smarter cities does not take place in a vacuum. Therefore, the ways in which city systems are currently organised will necessarily influence the process and impact of introducing new intermediaries, or substituting existing ones, through the digital dimension (see P2). Changes are also likely to be required in the ways the currently existing sociotechnical city systems operate to accommodate the nascent digital dimension and to be able to harness the benefits that it offers. As the chief digital officer of the UK Ministry of Housing, Communities and Local Government said, 'you can't bolt AI onto legacy systems and mindsets' (Nesta City Data Conference: from Analytics to AI, 24 May 2018). An investigation into the potential of digital boundary objects in supporting truly smart (Cavada et al., 2017) city development which results in better outcomes for the citizens and urban societies needs to extend to digital solutions' requirements and impact on the internal structure and processes of the local authority, its role and position relative to public-sector bodies on other political-organisational levels as well as to organisations and individuals from the market sector and civil society.

\section{Conclusions}

This paper provides a critical review of the smart city literature informed by the sociotechnical perspective. The authors have 
argued for the benefits of considering the smart development of cities (and regions) as a dynamic change process in contrast with the currently dominant smart city narrative based on an interpretation of the smart city as a static, normative goal. The process perspective highlights the role of society and governance alongside technology innovation and adoption. It also implies the need for a supply (technology push)-demand (societal needs/pull) realignment to shed light on windows of opportunities in the context of the ongoing digital revolution where impact can be delivered to explore and demonstrate the value of data to support the development of smarter cities. This in turn is crucial to build trust in and competence for the adoption and use of data and digital technologies for city planning, management, operation and use.

The process of developing smarter cities is far from being 'emergent' or 'natural'. Instead, it results from conscious choices and decisions made by diverse societal actors in different urban settings characterised by varying historical, cultural and political environments. Consequently, politics (in the broadest sense of the word) cannot be ignored: the development of smarter cities involves questions around access to, and influence over, decisionmaking for smarter city futures. The authors have argued that the development of the digital dimension of the city is a sociotechnical process and therefore must be scrutinised and debated as such, rather than being considered as a purely technical-managerial question. This shift in focus is absolutely necessary to be able to link the digital to smart.

Future scientific enquiry must pay attention to the potential of this nascent digital dimension to reorganise relationships and interactions among entities and objects in both the social world and the built (and natural) environment of cities. Taking a relational perspective thus can contribute to building a better understanding of the possible smarter city futures and the associated implications - for example, in terms of the redistribution of political and market powers.

The authors introduced a relational perspective as a useful framing to start investigating these issues, informed by notions of boundary spanning (which ultimately may also lead to the removal of boundaries in certain cases) and the coordination and management of this process. The concept of boundary objects was used to build a better understanding of how novel digital technologies and data-driven solutions may reorganise existing patterns of relationships and interactions in cities. An example that much of the discussion presented here focused on the ongoing restructuration process from sectoral to territorial infrastructures and associated services, through improving system integration and interoperability and reducing sectoral silos across, for example, transport, energy or water provision, as well as healthcare, social care and education.

The relational perspective provides a coherent framework for understanding the role of the digital, in terms of both individual technical solutions and the emerging digital dimension of the city in facilitating smart city development. This raises questions of who gains and who loses as a result of the ongoing digitalisation processes in cities. Better city-level outcomes often promised by technology companies and the digital solutions that they promote must explicitly aim at improving the democratic, economic and environmental performance of cities to be considered as part of the smart city development process.

\section{Acknowledgements}

This paper was developed based on the work and discussions taking place within the frames of the 'Digital Cities for Change' project at the Centre for Smart Infrastructure and Construction (CSIC), Department of Engineering, University of Cambridge. The authors would like to thank the members of the project's Steering Group for their insightful and invaluable comments and feedback which helped in evolving this paper. The Steering Group members include colleagues from The Ove Arup Foundation, Arup, University College London, University of Oxford, the Future Cities Catapult and the Greater London Authority. This work was supported by the Ove Arup Foundation and the CSIC (grant reference: RG89525), Department of Engineering, University of Cambridge, Cambridge, UK.

\section{REFERENCES}

Albino V, Berardi U and Dangelico RMR (2015) Smart cities: definitions, dimensions, performance, and initiatives. Journal of Urban Technology 22(1): 1-19, https://doi.org/10.1080/10630732.2014.942092.

Amin A (2014) Lively infrastructure. Theory, Culture \& Society 31(8): 137-161, https://doi.org/10.1177/0263276414548490.

Anand N (2017) Hydraulic City: Water and the Infrastructures of Citizenship in Mumbai. Duke University Press, Durham, NC, USA. See http://www.oapen.org/search?identifier=625674 (accessed 24/04/ 2018).

Anthopoulos L (2017) Smart utopia VS smart reality: learning by experience from 10 smart city cases. Cities 63: 128-148, https://doi. org/10.1016/j.cities.2016.10.005.

Arup and FCC (Future Cities Catapult) (2017) Smart City Strategies: A Global Review 2017. Arup and FCC, London, UK. See https://www. arup.com/publications/research/section/smart-city-strategies-a-globalreview (accessed 07/03/2018).

Barrie J, Zawdie G and João E (2017) Leveraging triple helix and system intermediaries to enhance effectiveness of protected spaces and strategic niche management for transitioning to circular economy. International Journal of Technology Management \& Sustainable Development 16(1): 25-47, https://doi.org/10.1386/tmsd.16.1.25_1.

Batty M (2017) The Age of the Smart City. Centre for Advanced Spatial Analysis, University College London, London, UK.

Bekkers V and Edwards A (2007) Legitimacy and democracy: a conceptual framework for assessing governance practices. In Governance and the Democratic Deficit: Assessing the Democratic Legitimacy of Governance Practices (Bekkers V, Dijkstra G, Edwards A and Fenger M (eds)). Ashgate, Aldershot, UK, pp. 35-60. See https://repub.eur.nl/pub/90149/ (accessed 09/06/2018).

Berkhout F and Hertin J (2001) Impacts of Information and Communication Technologies on Environmental Sustainability: Speculations and Evidence - Report to the OECD. Organisation for Economic Co-operation and Development, Paris, France. See http:// www.ictliteracy.info/rf.pdf/OECD-ICT-EnvrnmtImpct.pdf (accessed 25/05/2019).

Bibri SE (2018) Backcasting in futures studies: a synthesized scholarly and planning approach to strategic smart sustainable city development. 
European Journal of Futures Research 6(1): 13, https://doi.org/10. 1186/s40309-018-0142-z.

Bogason P and Musso JAJ (2006) The democratic prospects of network governance. American Review of Public Administration 36(1): 3-18, https://doi.org/10.1177/0275074005282581.

BSI (2014) PAS 181:2014: Smart city framework. Guide to establishing strategies for smart cities and communities. BSI, London, UK.

Capdevila I and Zarlenga MI (2015) Smart city or smart citizens? The Barcelona case. Journal of Strategy and Management 8(3): 266-282, https://doi.org/10.1108/JSMA-03-2015-0030.

Carlile PR (2002) A pragmatic view of knowledge and boundaries: boundary objects in new product development. Organization Science 13(4): 442-455, https://doi.org/10.1287/orsc.13.4.442.2953.

Carlile PR (2004) Transferring, translating, and transforming: an integrative framework for managing knowledge across boundaries. Organization Science 15(5): 555-568, https://doi.org/10.1287/orsc.1040.0094.

Cash D, Clark W, Alcock F et al. (2003) Salience, Credibility, Legitimacy and Boundaries: Linking Research, Assessment and Decision Making. John F. Kennedy School of Government, Harvard University, Cambridge, MA, USA.

Castells M (2010) Globalisation, networking, urbanisation: reflections on the spatial dynamics of the information age. Urban Studies 47(13): 2737-2745, https://doi.org/10.1177/0042098010377365.

Cavada M, Hunt D and Rogers C (2017) The Little Book of Smart Cities. ImaginationLancaster, Lancaster, UK. See http://liveablecities.org.uk/ sites/default/files/outcome downloads/littlebookofsmartcities.pdf (accessed 29/04/2019)

Choi T and Chandler SM (2015) Exploration, exploitation, and public sector innovation: an organizational learning perspective for the public sector. Human Service Organizations: Management, Leadership \& Governance 39(2): 139-151, https://doi.org/10.1080/23303131.2015. 1011762

Cocchia A (2014) Smart and digital city: a systematic literature review. In Smart City: How to Create Public and Economic Value with High Technology in Urban Space (Dameri R and Rosenthal-Sabroux C (eds)). Springer, Cham, Switzerland, pp. 13-43.

Cumbie BA and Sankar CS (2012) Choice of governance mechanisms to promote information sharing via boundary objects in the disaster recovery process. Information Systems Frontiers 14(5): 1079-1094, https://doi.org/10.1007/s10796-011-9338-5.

Datta A (2015) A 100 smart cities, a 100 utopias. Dialogues in Human Geography 5(1): 49-53, https://doi.org/10.1177/2043820614565750.

Dilling L and Lemos MC (2011) Creating usable science: opportunities and constraints for climate knowledge use and their implications for science policy. Global Environmental Change 21(2): 680-689, https:// doi.org/10.1016/j.gloenvcha.2010.11.006.

Dodgson M (1993) Organizational learning: a review of some literatures Organization Studies 14(3): 375-394, https://doi.org/10.1177/ 017084069301400303.

Dunleavy P, Margetts H, Tinkler J and Bastow S (2006) Digital Era Governance: IT Corporations, the State, and E-Government. Oxford University Press, Oxford, UK.

Edelman BG and Geradin D (2015) Efficiencies and regulatory shortcuts: how should we regulate companies like Airbnb and Uber? Stanford Technology Law Review 19(2): 293-328, https://doi.org/10.2139/ssrn. 2658603.

FCC (Future Cities Catapult) (2018) Smart City Demonstrators - a Global Review of Challenges and Lessons Learned. FCC, London, UK. See $\mathrm{http}$ ///futurecities.catapult.org.uk/resource/smart-city-demonstrators-aglobal-review-of-challenges-and-lessons-learned/ (accessed 25/05/ 2019).

Fedorowicz J and Gogan JL (2010) Reinvention of interorganizational systems: a case analysis of the diffusion of a bio-terror surveillance system. Information Systems Frontiers 12(1): 81-95, https://doi.org/ 10.1007/s10796-009-9167-y
Fong A, Valerdi R and Srinivasan J (2007) Boundary objects as a framework to understand the role of systems integrators. Systems Research Forum 2(1): 11-18, https://doi.org/10.1142 S1793966607000042.

Garcia R and Calantone R (2002) A critical look at technological innovation typology and innovativeness terminology: a literature review. Journal of Product Innovation Management 19(2): 110-132, https://doi.org/10.1016/S0737-6782(01)00132-1.

Geels FW (2002) Technological transitions as evolutionary reconfiguration processes: a multi-level perspective and a case-study. Research Policy 31(8-9): 1257-1274, https://doi.org/10.1016/S0048-7333(02)00062-8.

Geels FW (2005) The dynamics of transitions in socio-technical systems: a multi-level analysis of the transition pathway from horse-drawn carriages to automobiles (1860-1930). Technology Analysis \& Strategic Management 17(4): 445-476, https://doi.org/10.1080/ 09537320500357319.

Geels FW and Kemp R (2007) Dynamics in socio-technical systems: typology of change processes and contrasting case studies. Technology in Society 29(4): 441-455, https://doi.org/10.1016/j.techsoc.2007.08.009.

Geels FW and Schot J (2007) Typology of sociotechnical transition pathways. Research Policy 36(3): 399-417, https://doi.org/10.1016/j. respol.2007.01.003.

Genus A and Coles AM (2008) Rethinking the multi-level perspective of technological transitions. Research Policy 37(9): 1436-1445, https:// doi.org/10.1016/j.respol.2008.05.006.

Ghertner DA (2011) Gentrifying the state, gentrifying participation: elite governance programs in Delhi. International Journal of Urban and Regional Research 35(3): 504-532, https://doi.org/10.1111/j.14682427.2011.01043.x.

GLA (Greater London Authority) (2013) Smart London Plan: Using the Creative Power of New Technologies to Serve London and Improve Londoners' Lives. GLA, London, UK. See https://www.london.gov.uk/ sites/default/files/smart_london_plan.pdf (accessed 25/05/2019).

GLA (2018) Smarter London Together: the Mayor's Roadmap to Transform London into the Smartest City in the World. GLA, London, UK. See https://www.london.gov.uk/sites/default/files/ smarter london together v1.66 - published.pdf (accessed 25/05/ 2019).

Goodspeed R (2014) Smart cities: moving beyond urban cybernetics to tackle wicked problems. Cambridge Journal of Regions, Economy and Society 8(1): 79-92, https://doi.org/10.1093/cjres/rsu013.

Graham S and Marvin S (2001) Splintering Urbanism: Networked Infrastructures, Technological Mobilities and the Urban Condition. Routledge, Abingdon, UK.

Haarstad H (2017) Constructing the sustainable city: examining the role of sustainability in the 'smart city' discourse. Journal of Environmental Policy and Planning 19(4): 423-437, https://doi.org/10. 1080/1523908X.2016.1245610.

Harrison C, Eckman B, Hamilton R et al. (2010) Foundations for smarter cities. IBM Journal of Research and Development 54(4): 1-16, https:// doi.org/10.1147/JRD.2010.2048257.

Hemment D and Townsend A (2013) Smart Citizens. FutureEverything, Manchester, UK. See https://core.ac.uk/download/pdf/153534188.pdf (accessed 29/04/2019)

Hollands RG (2008) Will the real smart city please stand up? Intelligent, progressive or entrepreneurial? City 12(3): 303-320, https://doi.org/10. 1080/13604810802479126.

Hollands RG (2015) Critical interventions into the corporate smart city. Cambridge Journal of Regions, Economy and Society 8(1): 61-77, https://oi.org/10.1093/cjres/rsu011.

Hoogma R, Kemp R, Schot J and Truffer B (2002) Experimenting for Sustainable Transport: the Approach of Strategic Niche Management. Routledge, Abingdon, UK.

Hussenot A and Missonier S (2010) A deeper understanding of evolution of the role of the object in organizational process: the concept of 
'mediation object'. Journal of Organizational Change Management 23(3): 269-286, https://doi.org/10.1108/09534811011049608.

Jaglin S (2015) Is the network challenged by the pragmatic turn in African cities? Urban transition and hybrid delivery configurations. In Beyond the Networked City: Infrastructure Reconfigurations and Urban Change in the North and South (Coutard O and Rutherford J (eds)). Routledge, Abingdon, UK, pp. 200-221.

Kimble C, Grenier C and Goglio-Primard K (2010) Innovation and knowledge sharing across professional boundaries: political interplay between boundary objects and brokers. International Journal of Information Management 30(5): 437-444, https://doi.org/10.1016/j. ijinfomgt.2010.02.002.

Kitchin R (2014) The real-time city? Big data and smart urbanism. GeoJournal 79(1): 1-14, https://doi.org/10.1007/s10708-013-9516-8.

Kitchin R (2016) The ethics of smart cities and urban science. Philosophical Transactions of the Royal Society A: Mathematical, Physical and Engineering Sciences 374(2083): 20160115, https://doi. org/10.1098/rsta.2016.0115.

Kitchin R, Lauriault TP and McArdle G (2017) Data and the City. Routledge, Abingdon, UK.

Kivimaa P, Boon W, Hyysalod S and Klerkxe L (2019) Towards a typology of intermediaries in sustainability transitions: a systematic review and a research agenda. Research Policy 48(4): 1062-1075, https://doi.org/ 10.1016/j.respol.2018.10.006.

Klijn EH and Koppenjan J (2012) Governance network theory: past, present and future. Policy \& Politics 40(4): 587-606, https://doi.org/ 10.1332/030557312X655431.

Klijn HE and Koppenjan J (2015) Governance Networks in the Public Sector. Routledge, Abingdon, UK.

Knox H (2017) Affective infrastructures and the political imagination. Public Culture 29(2 (82)): 363-384, https://doi.org/10.1215/089923633749105.

Kuipers BS, Higgs M, Kickert W et al. (2014) The management of change in public organizations: a literature review. Public Administration 92(1): 1-20, https://doi.org/10.1111/padm.12040

Lam A (2000) Tacit knowledge, organizational learning and societal institutions: an integrated framework. Organization Studies 21(3): 487-513, https://doi.org/10.1177/0170840600213001.

Lancione M and McFarlane C (2016) Life at the urban margins: sanitation infra-making and the potential of experimental comparison. Environment and Planning A 48(12): 2402-2421, https://doi.org/10. 1177/0308518X16659772.

Leach JM, Rogers CDF, Ortegon-Sanchez A and Tyler N (2018) The Liveable Cities Method: establishing the case for transformative change for a UK metro. Proceedings of the Institution of Civil Engineers - Engineering Sustainability, https://doi.org/10.1680/jensu. 18.00028.

Lemanski C (2017) Unequal citizenship in unequal cities: participatory urban governance in contemporary South Africa. International Development Planning Review 39(1): 15-35, https://doi.org/10.3828/ idpr.2017.2

Lindgren R, Andersson M and Henfridsson O (2008) Multi-contextuality in boundary-spanning practices. Information Systems Journal 18(6): 641-661, https://doi.org/10.1111/j.1365-2575.2007.00245.x.

Lombardi P, Giordano S, Farouh H and Yousef W (2012) Modelling the smart city performance. Innovation 25(2): 137-149, https://doi.org/10. 1080/13511610.2012.660325.

Luque-Ayala A and Marvin S (2015) Developing a critical understanding of smart urbanism? Urban Studies 52(12): 2105-2116, https://doi.org/ 10.1177/0042098015577319.

Maheshwari D and Janssen M (2014) Reconceptualizing measuring, benchmarking for improving interoperability in smart ecosystems: the effect of ubiquitous data and crowdsourcing. Government Information Quarterly 31(Supplement 1): S84-S92, https://doi.org/10.1016/j.giq. 2014.01.009.
Margetts H and Dunleavy P (2013) The second wave of digital-era governance: a quasi-paradigm for government on the Web. Philosophical Transactions of the Royal Society A: Mathematical, Physical and Engineering Sciences 371(1987): 1-17, https://doi.org/ 10.1098/rsta.2012.0382.

Martin CJ, Evans J and Karvonen A (2018) Smart and sustainable? Five tensions in the visions and practices of the smart-sustainable city in Europe and North America. Technological Forecasting and Social Change 133: 269-278, https://doi.org/10.1016/j.techfore.2018.01.005.

Meijer A and Bolívar MPR (2016) Governing the smart city: a review of the literature on smart urban governance. International Review of Administrative Sciences 82(2): 392-408, https://doi.org/10.1177/ 0020852314564308.

Meijer AJ, Gil-Garcia JR and Bolívar MPR (2016) Smart city research: contextual conditions, governance models, and public value assessment. Social Science Computer Review 34(6): 647-656, https:// doi.org/10.1177/0894439315618890.

Meuleman L (2008) Public Management and the Metagovernance of Hierarchies, Networks and Markets. Physica-Verlag, Heidelberg, Germany.

Monfaredzadeh T and Krueger R (2015) Investigating social factors of sustainability in a smart city. Procedia Engineering 118: 1112-1118, https://doi.org/10.1016/j.proeng.2015.08.452.

Monstadt J and Schramm S (2017) Toward the networked city? translating technological ideals and planning models in water and sanitation systems in Dar es Salaam. International Journal of Urban and Regional Research 41(1): 104-125, https://doi.org/10.1111/1468-2427. 12436.

Nam T and Pardo TA (2011) Conceptualizing smart city with dimensions of technology, people, and institutions. Proceedings of the 12th Annual International Digital Government Research Conference on Digital Government Innovation in Challenging Times, College Park, $M D$, USA, pp. 282-291.

Neff G, Fiore-Silfvast B and Dossick CS (2010) A case study of the failure of digital communication to cross knowledge boundaries in virtual construction. Information Communication and Society 13(4): 556-573, https://doi.org/10.1080/13691181003645970.

Neirotti P, De Marco A, Cagliano AC, Mangano G and Scorrano F (2014) Current trends in smart city initiatives: some stylised facts. Cities 38: 25-36, https://doi.org/10.1016/j.cities.2013.12.010.

Newton K, Stolle D and Zmerli S (1999) Social and political trust. In The Oxford Handbook of Social and Political Trust (Uslaner EM (ed.)). Oxford University Press, Oxford, UK, pp. 37-56.

Ormerod P (2005) Why Most Things Fail: Evolution, Extinction and Economics. Wiley, Chichester, UK.

Osborne SP (2010) The New Public Governance: Emerging Perspectives on the Theory and Practice of Public Governance. Routledge, Abingdon, UK

Paskaleva K, Evans J, Martin C et al. (2017) Data governance in the sustainable smart City. Informatics 4(4): 41, https://doi.org/10.3390/ informatics4040041.

Phdungsilp A (2011) 'Futures studies' backcasting method used for strategic sustainable city planning. Futures 43(7): 707-714, https://doi. org/10.1016/j.futures.2011.05.012.

Pollitt C and Bouckaert G (2004) Public Management Reform: a Comparative Analysis. Oxford University Press, Oxford, UK.

Pollitt C and Bouckaert G (2011) Public Management Reform - $a$ Comparative Analysis: New Public Management, Governance, and the Neo-Weberian State. Oxford University Press, Oxford, UK.

Potts J (2009) The innovation deficit in public services: the curious problem of too much efficiency and not enough waste and failure. Innovation: Management, Policy and Practice 11(1): 34-43, https:// doi.org/10.5172/impp. 453.11.1.34.

Rabari C and Storper M (2015) The digital skin of cities: urban theory and research in the age of the sensored and metered city, ubiquitous 
computing and big data. Cambridge Journal of Regions, Economy and Society 8(1): 27-42, https://doi.org/10.1093/cjres/rsu021.

Rhodes RAW (1996) The new governance: governing without government. Political Studies 44(4): 652-667, https://doi.org/10.1111/ j.1467-9248.1996.tb01747.x.

Rittel HWJ and Webber MM (1973) Dilemmas in a general theory of planning. Policy Sciences 4(2): 155-169, https://doi.org/10.1007/ BF01405730.

Robinson C (2018) Society in the Loop - a One Day Event. Medium, San Francisco, CA, USA. See https://medium.com/doteveryone/ society-in-the-loop-a-one-day-event-3d552ea9c029 (accessed 01/05/ 2019).

Rogers CD (2018) Engineering future liveable, resilient, sustainable cities using foresight. Proceedings of the Institution of Civil Engineers Civil Engineering 171(6): 3-9, https://doi.org/10.1680/jcien.17.00031.

Rogers CD, Shipley J, Blythe P et al. (2014) Future Urban Living: a Policy Commission Investigating the Most Appropriate Means for Accommodating Changing Populations and Their Needs in the Cities of the Future. University of Birmingham, Birmingham, UK. See https:/www.birmingham.ac.uk/Documents/research/policycommission/ future-urban-living/future-urban-living-policy-commission-report.pdf (accessed 01/05/2019).

Rose G (2017) Posthuman agency in the digitally mediated city: exteriorization, individuation, reinvention. Annals of the American Association of Geographers 107(4): 779-793, https://doi.org/10.1080/ 24694452.2016.1270195.

Rotmans J, Kemp R and van Asselt M (2001) More evolution than revolution: transition management in public policy. Foresight 3(1): 15-31, https://doi.org/10.1108/14636680110803003.

Shwayri ST (2013) A model Korean ubiquitous eco-city? The politics of making Songdo. Journal of Urban Technology 20(1): 39-55, https:// doi.org/10.1080/10630732.2012.735409.

Skelcher C (2000) Changing images of the State: overloaded, hollowedout, congested. Public Policy and Administration 15(3): 3-19, https:// doi.org/10.1177/095207670001500302.

Star SL (1999) The ethnography of infrastructure. American Behavioral Scientist 43(3): 377-391, https://doi.org/10.1177/00027649921955326.

Star SL (2010) This is not a boundary object: reflections on the origin of a concept. Science Technology and Human Values 35(5): 601-617, https://doi.org/10.1177/0162243910377624.

Star SL and Griesemer JR (1989) Institutional ecology, 'translations' and boundary objects: amateurs and professionals in Berkeley's Museum of Vertebrate Zoology, 1907-39. Social Studies of Science 19(3): 387-420, https://doi.org/10.1177/030631289019003001.

Stone B (2017) The Upstarts: How Uber, Airbnb, and the Killer Companies of the New Silicon Valley Are Changing the World. Little, Brown and Company, New York, NY, USA.

Swyngedouw E (2009) The political economy and political ecology of the hydro-social cycle. Journal of Contemporary Water Research \& Education 142(1): 56-60, https://doi.org/10.1111/j.1936-704X.2009. 00054.x.

Tarute A and Gatautis R (2014) ICT impact on SMEs performance. Procedia - Social and Behavioral Sciences 110: 1218-1225, https:// doi.org/10.1016/j.sbspro.2013.12.968.

Taylor PG, Upham P, McDowall W and Christopherson D (2014) Energy model, boundary object and societal lens: 35 years of the MARKAL model in the UK. Energy Research and Social Science 4(C): 32-41, https://doi.org/10.1016/j.erss.2014.08.007.

Toaf (The Ove Arup Foundation) (2019) Digital Cities for Change - Ove Arup Foundation. Toaf, London, UK. See http://www. ovearupfoundation.org/featured-grants/digital-cities-for-change (accessed 01/05/2019).

Tolbert CJ and Mossberger K (2006) The effects of E-government on trust and confidence in government. Public Administration Review 66(3): 354-369, https://doi.org/10.1111/j.1540-6210.2006.00594.x.
Torfing J (2005) Governance network theory: towards a second generation. European Political Science 4(3): 305-315, https://doi.org/ 10.1057/palgrave.eps.2210031.

Torfing J and Sørensen E (2014) The European debate on governance networks: towards a new and viable paradigm? Policy and Society 33(4): 329-344, https://doi.org/10.1016/j.polsoc.2014.10.003.

Townsend AM (2013) Smart Cities: Big Data, Civic Hackers and the Quest for a New Utopia. W.W. Norton, New York, NY, USA.

Trompette P and Vinck D (2009) Revisiting the notion of boundary object. Revue d'anthropologie des connaissances 3(11): 3-25, https:// doi.org/10.3917/rac.006.0003.

van Kersbergen K and van Waarden F (2009) 'Governance' as a bridge between disciplines: cross-disciplinary inspiration regarding shifts in governance and problems of governability, accountability and legitimacy. In European Corporate Governance. Readings and Perspectives (Clarke T and Chanlat JF (eds)). Routledge, Abingdon, UK, pp. 64-80.

Viitanen J and Kingston R (2014) Smart cities and green growth: outsourcing democratic and environmental resilience to the global technology sector. Environment and Planning A 46(4): 803-819, https://doi.org/10.1068/a46242.

Watson V (2014) African urban fantasies: dreams or nightmares? Environment and Urbanization 26(1): 215-231, https://doi.org/10. $1177 / 0956247813513705$.

Whyte J and Lobo S (2010) Coordination and control in project-based work: digital objects and infrastructures for delivery. Construction Management and Economics 28(6): 557-567, https://doi.org/10.1080/ 01446193.2010.486838.

Williamson B (2015) Governing software: networks, databases and algorithmic power in the digital governance of public education. Learning, Media and Technology 40(1): 83-105, https://doi.org/10. 1080/17439884.2014.924527.

Yigitcanlar T (2016) Technology and the City: Systems, Applications and Implications. Routledge, Abingdon, UK.

Yigitcanlar T and Kamruzzaman M (2018) Does smart city policy lead to sustainability of cities? Land Use Policy 73: 49-58, https://doi.org/10. 1016/j.landusepol.2018.01.034.

Young D and Keil R (2010) Reconnecting the disconnected: the politics of infrastructure in the in-between city. Cities 27(2): 87-95, https://doi. org/10.1016/j.cities.2009.10.002.

\section{How can you contribute?}

To discuss this paper, please email up to 500 words to the editor at journals@ice.org.uk. Your contribution will be forwarded to the author(s) for a reply and, if considered appropriate by the editorial board, it will be published as discussion in a future issue of the journal.

Proceedings journals rely entirely on contributions from the civil engineering profession (and allied disciplines). Information about how to submit your paper online is available at www.icevirtuallibrary.com/page/authors, where you will also find detailed author guidelines. 